\title{
Approaches in assessing the investment attractiveness of small towns of Russia
}

\author{
A. Emelianovich ${ }^{1, *}$, E. Kulyagina ${ }^{2}$, and $Y u$. Kolozhvari ${ }^{2}$ \\ ${ }^{1}$ Novosibirsk State University of Architecture and Civil Engineering (Sibstrin), 630008, Turgeneva \\ str., 159, Novosibirsk, Russia \\ ${ }^{2}$ Novosibirsk State University of Economics and Management, 630099, Kamenskaya str., 52, \\ Novosibirsk, Russia
}

\begin{abstract}
Effective use of the territories' resources depends on the development of small- and medium-sized business as the basis of high economic activity of the local population. In Russia small and mediumsized business is a priority vector of economic development, a factor of the gross domestic product increase, and of unemployment decline. The article describes a methodological approach to assess the development of small scale and medium-sized enterprises of the territory bearing in mind the adaptation of some known methods to the peculiarities of the regional economy. The authors also assessed the investment potential and investment attractiveness on the example of the town of Barabinsk of the Novosibirsk Region. The article proves that small and medium business has great potential for further development, giving rise to many promising projects; still the paper reveals some actual problems delaying the process of small and medium-sized enterprises expansion. In the conclusion some activities for further promotion and stimulation of small and medium business development in the town of Barabinsk are proposed.
\end{abstract}

\section{Introduction}

The segment of small and medium entrepreneurship is one of the leading directions, which determines the possibility and intensity of economic development of Russia, of employment and degree of quality of the gross national product. Taking into account small and medium business potential, we can say that in many respects it answers the main trends of the world development and forms a mixed economy, integrates different forms of ownership and, most importantly, serves as a bridge between state government support and control and competitive market mechanism. Small and medium business is the foundation to build the whole market economy on; it is this that makes small scale and medium-sized businesses particular significant for the economy.

Small and medium businesses in contrast to major market players consider local level of demand as a priority, giving preference to the specific needs of the consumer. It includes specialized products and services, and innovations, while big business sees its principal

\footnotetext{
*Corresponding author: kristimof@yandex.ru
} 
goal in providing the basic needs of the population and the state. In general, small and medium business can be viewed as an independent player within the market niche it occupies, thanks to the lower production costs.

Naumov E.B. notes that the integrated development of the country and regions, as well as the potential of small- and medium-sized businesses, closely linked to the problem of attracting financial resources. Nowadays, the regions are relatively independent in their development due to the decentralization of authority. It means that the local authorities' essential task is to develop the programs on attracting investment in small and medium business of the region [6].

According to Kovalenko E. G., due to the fact that regional authorities are limited in their financial recourses, the key areas of the economy, including small-1 and medium-sized businesses suffer from the funding gap. In these circumstances, the efforts to increase investment flows from commercial investors by improving investment attractiveness should be brought to the forefront [3].

The investment attractiveness is understood as a set of processes and factors that determine the investment behavior of investment entities in the region [4].

The degree of investment attractiveness of small and medium business of the region is evaluated according to a complex of factors, which should reflect both the inner state of the firm and the character of the environmental surrounding. The internal state of the firm directly depends on the processes taking place in it, while the rating of investment attractiveness depends on investment efficiency indicators, the company can control by using its leverage.

In Russia small and medium business has not been developed to play the role of the principal reformer of the economy, but now we can observe the huge potential of this segment, that allows to consider it as one of the main factors in the development of the economy, as the opportunities of entrepreneurship in Russia are not exhausted, moreover, up to now they haven't been used sufficiently.

Small and medium business has great potential for further development, giving rise to many promising projects. And still the problem hindering the process of small and medium business expanding could be unveiled as the problem of insufficient level of financing, or even the lack of funding, which in its turn is caused by the low stability and high risk of this type of business. This may also include insufficient government support, low investment opportunities of non-state institutions, high interest rates and strict criteria of commercial banks and other organizations.

When working on this article the authors used the following normative legal acts in the field of entrepreneurship: Federal law of 24 July 2007 No 209-FZ "On development of small and medium-sized enterprises in the Russian Federation"; Federal law of 08 August 2001 No. 129-FZ "On state registration of legal entities and individual entrepreneurs"; Federal law of April 05, 2013 №44-FZ "On contract system in procurement of goods, works, services for state and municipal needs"; Federal law of 26 July 2006 No. 135-FZ "On competition protection"; the Novosibirsk region law of 02.07.2008 No. 245-OZ "On development of small and medium-sized enterprises in the Novosibirsk region"; the Novosibirsk region law from16.10.2003 No. 142-OZ "On taxes and features of taxation of particular categories of taxpayers in the Novosibirsk region"; a schedule plan (road map) for development of small and medium enterprises in 2017 in the Novosibirsk region, as well as statistical data of the Russian Federation and the Novosibirsk region.

The relevant scientific literature on the research topic served as methodological and informative framework of the article, together with educational and methodical manuals of the following authors: Ivashentseva, T. A., Slastyonova K. I., Bondareva O. V., Misich M. A., Visotskaya O.A., Rabtsevich A. A., Khasanova G. A., Dunaeva, A. I., Abalova N. O., Udain N. O., Akimov O. Yu., Maslov, L. V., Belokorovin E. A., Terebova S. V., 
Podolyakin O. V., Uskov V. S., Egorkina S. Yu., Volkova-Goncharova T. A., Gozman O., Moiseeva N. K.

The authors draw upon experience of such foreign researches as Fox Jeffrey J., Shrivenham Ali, Hayek F., Shumpert I., Coase R.

\section{Experiments}

The integral index of investment potential is one of the methods of assessment of the region investment attractiveness. The methodology is based on the determination of the investment potential levels and risk of the region; it gives an opportunity to use a complex approach to the analyzed situation [5].

Indicators which are investment significant in the calculation of the integral index of the investment attractiveness:

I. Indicators of the investment potential of the territory.

A. Economic and investment potential:

- GRP per capita, RUB.;

- investments in fixed assets per capita, RUB.;

- volume index for investments, \% to previous year;

- trade turnover, million rubles.

B. Productive and financial potential:

- industrial production index, \% to the previous year;

- share of employment in the SMBs, \% of total employment;

- volume of innovative products, (million rubles);

- retail trade turnover per capita, RUB.;

- volume of paid services per capita, RUB.;

- amount of work performed in construction, mln RUB.;

- agricultural products, million rubles

Social potential:

- density of roads, (km per 1000 square $\mathrm{km}$ of the territory);

- housing area implementation per 1,000 persons (square meters of the total area);

- economically active population, thousand people;

- average cash income for the population, RUB./ a month.

II. Indicators of socio-economic and environmental security.

- number of unemployed, thousand people;

- specific weight of loss-making enterprises, $\%$ from total number of organizations;

- number of registered crimes per 100000 people;

- population with monetary incomes below the subsistence minimum, $\%$ of the total population.

Usual way to calculate the value of these indicators is to use information resources of statistics, various research studies, as well as competent experts survey.

As the indicators of the investment potential are diverse, in order to be reduced to the integrated index they need to be estimated by the formula 1 [1], which is taken to be multivariate. This formula is used quite frequently in the studies of the regional economy. But first, values of partial indicators should be reduced to common quantity. This procedure is called standardization and is carried out by classifying values of each partial index of the region to the standard deviation of these indicators. 


$$
\mathrm{X}_{\mathrm{it}}^{\text {Pot }}=\frac{\sum_{s=1}^{\mathrm{n}} \mathrm{x}_{\mathrm{sit}}^{\mathrm{Pot}} \times \mathrm{k}_{s \mathrm{t}}^{\text {Pot }}}{\sum_{s=1}^{\mathrm{n}} \mathrm{k}_{s \mathrm{t}}^{\text {Pot }}}
$$

where

$\mathrm{X}_{\mathrm{it}}^{\text {Pot }}$ - integral indicator of the investment potential of the $\mathrm{t}$-th year of the $\mathrm{i}$-th region;

$\mathbf{k}_{\mathrm{st}}^{\text {Pot }}$ - weighting factor of significance of the s-th partial indicator of the investment potential in the t-th year;

$\mathrm{n}$ - number of standardized partial indicators, which are the factors of the formation of the integral level of regions investment potential;

$\mathrm{t}$ - number of years of the period under review;

$\mathrm{s}-$ the number of partial indicators;

$\mathbf{x}_{\text {sit }}^{\text {Pot }}-$ the value of the s-th partial standardized indicator of the i-th region in the $t$-th year.

Partial indicators are ranked in accordance with the level of their significance, on condition that the socio-economic and environmental indicators are to be calculated inversely.

Each indicator of investment potential has its own weighting factor in percentage terms, the summation of which provides a result equal to $100 \%$. These factors are presented in table 1 .

Table 1. The value of the weighting coefficients of the investment-relevant indicators.

\begin{tabular}{|l|l|}
\hline Indicator & Weighting coefficient, \% \\
\hline GRP per capita & 15 \\
\hline Investments in fixed assets per capita & 12 \\
\hline Volume index for investments & 9 \\
\hline Industrial production index & 5 \\
\hline Share of employment in the SMBs & 7 \\
\hline Retail trade turnover per capita, & 5 \\
\hline Amount of work performed in construction & 7 \\
\hline Agricultural products & 2 \\
\hline Density of roads & 3 \\
\hline Number of telephones & 4 \\
\hline Housing area implementation per 10000 persons & 5 \\
\hline Economically active population & 3 \\
\hline Average cash income for the population & 3 \\
\hline Number of unemployed & 7 \\
\hline Specific weight of loss-making enterprises & 5 \\
\hline Number of registered crimes per 100 000 people & 4 \\
\hline $\begin{array}{l}\text { Population with monetary incomes below the } \\
\text { subsistence minimum }\end{array}$ & 4 \\
\hline
\end{tabular}

The obtained result should be compared with the values in table 2 .

Table 2. Classification of regions according to the degree of their investment attractiveness.

\begin{tabular}{|l|l|}
\hline Characteristic of the region & Index value \\
\hline Most investment attractive region & 0,4 or more \\
\hline High attractiveness of the region & $0,1776-0,3999$ \\
\hline Average attractiveness of the region & 0,1775 \\
\hline Attractiveness of below-average & $0,06,-0,1774$ \\
\hline Minimum attractiveness & Less than 0,0599 \\
\hline
\end{tabular}


This method gives an opportunity to gain a complex objective assessment of investment attractiveness of the region if to compare it with other regions in the light of the influence of various external and internal factors. It should be noted that calculations could be based on a greater number of factors, however, only those that are most significant for investments and may affect them are taken into account.

\section{Results}

According to the Decree of the Government of the Novosibirsk region No. 14-p on approval of the state program of the Novosibirsk region "Development of small and medium-sized enterprises in the Novosibirsk region in 2017-2022", small and medium business is one of the priorities of the region policy [7].

As of today, we can observe some stability and a slight increase in the total number of small and medium-sized businesses, shown in figure 1.

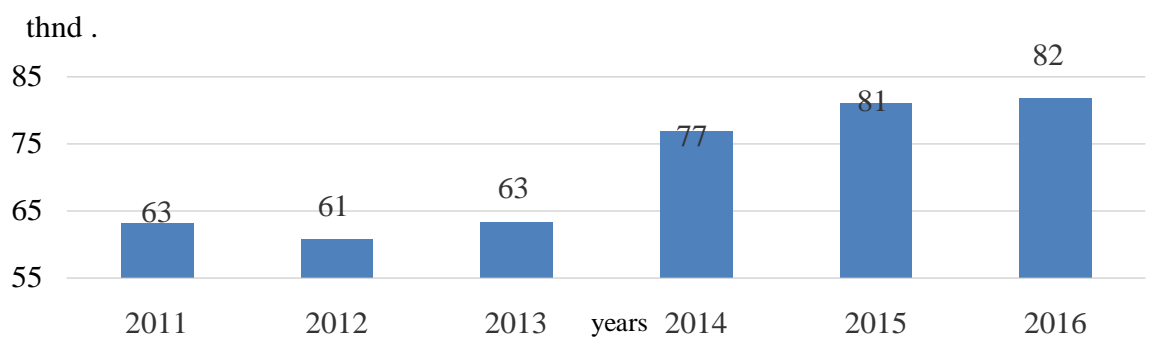

Fig. 1. Dynamics of the number of small and medium-sized enterprises in the Novosibirsk region [9].

From the figure given above we can see that the dynamics of the number of enterprises of small- and medium-sized business of the Novosibirsk region is generally fits well with the tendencies inherent to the Russian Federation.

To calculate the integral index of the investment potential of the town of Barabinsk we used the above information together with statistical data. Statistics are presented in table 3.

Table 3. The data required for the calculation of the integral indicator.

\begin{tabular}{|l|c|}
\hline Indicator & Indicator value \\
\hline GRP per capita & 212352 \\
\hline Investments in fixed assets per capita, thousand RUB & 331,5 \\
\hline Volume index for investments \% & 50,5 \\
\hline Industrial production index \% & 97,8 \\
\hline Share of employment in the SMBs \% & 8,9 \\
\hline Retail trade turnover per capita, mln RUB & 2718,3 \\
\hline Volume of paid services per capita & - \\
\hline Amount of work performed in construction, mln RUB & 231 \\
\hline Agricultural products, million rubles & 981 \\
\hline Density of roads, (km per 1000 square km of the territory) & 151 \\
\hline Number of telephones & 2 \\
\hline Housing area implementation, square meters per 1,000 persons & 199,47 \\
\hline Economically active population, thousand people; & 13499 \\
\hline Average cash income for the population, RUB. & 12675 \\
\hline Number of unemployed & 2377 \\
\hline
\end{tabular}




\begin{tabular}{|l|c|}
\hline Indicator & Indicator value \\
\hline Specific weight of loss-making enterprises, \% & 31 \\
\hline Air pollutant emissions & - \\
\hline Number of registered crimes per 100 000 people & 31,7 \\
\hline $\begin{array}{l}\text { Population with monetary incomes below the subsistence } \\
\text { minimum }\end{array}$ & 1954 \\
\hline
\end{tabular}

To standardize the values presented in table 3 we calculated the standard deviation, which is 51140,4 .

On this basis, the standardized values of the integral indicator were calculated, with the results presented in table 4 .

Table 4. The standardized values of the integral indicator.

\begin{tabular}{|l|c|}
\hline Indicator & Indicator value \\
\hline GRP per capita & 4,152334334 \\
\hline Investments in fixed assets per capita, thousand RUB & 0,006482156 \\
\hline Volume index for investments \% & 0,000987478 \\
\hline Foreign investments in the region economy & 0,001912383 \\
\hline Industrial production index \% & 0,000174031 \\
\hline Share of employment in the SMBs \% & 0,053153681 \\
\hline Retail trade turnover per capita, mln RUB & 0,004516978 \\
\hline Volume of paid services per capita & 0,019182489 \\
\hline Amount of work performed in construction, mln RUB & 0,002952656 \\
\hline Agricultural products, million rubles & 0,000039100 \\
\hline Density of roads, (km per 1000 square km of the territory) & 0,003900440 \\
\hline Number of telephones & 0,263959657 \\
\hline Housing area implementation, square meters per 1,000 persons & 0,247847149 \\
\hline Economically active population, thousand people; & 0,046479895 \\
\hline Average cash income for the population, RUB. & 0,000606174 \\
\hline Number of unemployed & 0,000619862 \\
\hline Specific weight of loss-making enterprises, \% & 0,038208547 \\
\hline Air pollutant emissions & 4,152334334 \\
\hline Number of registered crimes per 100 000 people & 0,006482156 \\
\hline $\begin{array}{l}\text { Population with monetary incomes below the subsistence } \\
\text { minimum }\end{array}$ & \\
\hline
\end{tabular}

On the basis of the presented data the integral indicator of the investment potential of the town of Barabinsk has been calculated. We used formula 1 for calculations.

The calculated value of the integral indicator is 0,006476586 .

In order to obtain the total summery value of the investment attractiveness of the town of Barabinsk formula 2 were used:

$$
\mathrm{IA}=\mathrm{Xi} * 1 / \mathrm{IR}
$$

where IA - is the desired integral index of investment attractiveness of the region;

$\mathrm{Xi}$ - integral indicator of the investment potential;

IR - average weighted index of the investment risk in the region.

According to statistics, the value of the average weighted index of the investment risk in the region is 0,215 .

The calculation of the total integral index of investment attractiveness of the town of Barabinsk is: $\mathrm{IA}=0,0064766 * 1 / 0,215=0,030123656$. 
This indicator provides the investor with the opportunity to determine the investment potential of the territory, and to compare it with those of other regions, i.e. this indicator could provide the total result only when being compared with other regions' indexes. However, this indicator is objective.

The result of the assessment, when being correlated with the data of table 2, revealed the unattractiveness of the town of Barabinsk for investors at the moment.

On the one hand, large-scale investment projects, as a part of reindustrialization program could be the ground for the town development, but they require fairly large investment resources, together with a long implementation period of the project. On the other hand, small and medium-sized business could be considered as the foundation of development of small towns, such as the town of Barabinsk. It surely is subjected to big risks in the period of recessionary phenomena in the economy, but is still more mobile and flexible when it comes to choosing the means to overcome he crisis.

It is necessary to diversify the sector nature of small businesses, to reveal priority sectors for financial support: today we observe a greater concentration of small scale business in retail trade, while young businessmen are willing to work in the real sector, and they also more willingly agree to work in other industry segments.

Besides, we'd like to identify competitive advantages, on the basis of which positive forecast for the development of small and medium businesses of the town of Barabinsk can be given:

1. Beneficial transport, economical and geographical position:

Barabinsk is an important railway junction of the Trans-Siberian Railway;

availability of a Federal highway M51 "Baikal" and regional paved road "ZdvinskArctic"; availability of the runway of the former airport.

2. The prospect of establishing the District Center for Economic Development and Social Service on the basis of the towns of Barabinsk and Kuibyshev (the distance between the towns is $10 \mathrm{~km}$, the total population of about 100 thousand inhabitants).

3. Mineral resources: large deposits of brick clay; proven reserves of peat.

4. Thevicinity of trunk high pressure gas pipeline.

5. Availability of sites for housing construction, construction of commercial buildings and industrial facilities, social infrastructure facilities.

6. Natural and climatic conditions for development of processing industry, including agricultural processing; availability of enterprises for the production of grain, milk, meat.

7. Availability of underused production capacity of plants.

8. Large cities such as Novosibirsk and Omsk are within reach; it provides additional possibilities in solving human resources policy (professional training in educational institutions); an effective marketing strategy makes this factor be crucial in providing additional opportunities for products marketing.

9. Active promotion of entrepreneurship by the city administration.

\section{Conclusion}

A great variety of methods of investment attractiveness of regions gives an opportunity to use the most relevant methods from the viewpoint of peculiarities of the region. The methodological approach described in the paper combines several approaches; it helps to assess the level of investment attractiveness of the region and to identify the potential of its growth. On the basis of the used methodology it is possible to conclude that the investment attractiveness of the town of Barabinsk is at a low level and the principal way of its development is the identification of "growth points" of the region and the development of labor potential necessary for the realization of the upcoming trends. 


\section{References}

1. A. N. Asaul, B. M. Karpov, V. B. Pereviaskin, M. K. Starovoitov. Modernization of the economy on the basis of technological innovations (ANO IPEV, SPb., 2008).

2. O. S. Zvyagintseva, the Economist, 9, 5-8 (2010)

3. E. G. Kovalenko, Regional economy and management (Piter, SPb., 2005).

4. I. L. Leontiev, Modeling of innovative and investment development of socially significant territorial objects: thesis abstract to receive a doctor degree of economic (Ekaterinburg, 2013).

5. V. V. Litvinova, Young Scientist, 4-1, 161-169 (2011)

6. V. N. Naumov, Organization of entrepreneurship (Piter, SPb., 2010)

7. Informational resource of the town of Barabinsk (http://www.berdskadm.ru/business /pred/program_mp)

8. Territorial Organ of the Federal State Statistics Service of the Novosibirsk Region (http://novosibstat.gks.ru, 2018)

9. M. Y. Veselovsky, M. A. Izmailova, A. V. Bogoviz, S. V. Lobova, A. N. Alekseev, Quality - Access to Success, 19(162), 60-66 (2018)

10. A. A. Emelianovich, E. A. Kulyagina, E.V. Tzurkan, Competitiveness in a global world: economy, science, technologies, 3-1 (32), $42-45$ (2017)

11. Yu. B. Kolozhvari, M. E. Pronina, Theoretical and practical aspects of the scientific thought development in the world today. Collected articles of the International scientific and practical conference, 144-147 (2016) 